\title{
Erratum to: Arteria praebronchialis found on MDCT: potentially dangerous aberrant artery supplying the left lower lobe
}

\author{
Ji Hyun Hong ${ }^{1} \cdot$ Hyun Jung Kim ${ }^{1} \cdot$ Dae Hee Han ${ }^{1} \cdot$ Sook Hwan Sung ${ }^{2} \cdot$ Myeong \\ Im Ahn ${ }^{1} \cdot$ Jung Im Jung ${ }^{1}$
}

Published online: 25 August 2015

(C) Springer-Verlag France 2015

\section{Erratum to: Surg Radiol Anat \\ DOI 10.1007/s00276-015-1455-2}

In the original publication of the article, the number of patients and the incidence value are incorrect. The authors would like to correct the numbers and values as given below:

In the Abstract section, the first sentence in the heading "Results" should read, "The estimated incidence of the AP was $0.05 \% "$.

In the Results section, the paragraph below the heading "Incidence" should read, "During the study period, contrast-enhanced chest CT scans of 5935 patients were interpreted by the radiologist (D.H.H.). The incidence of the AP was assessed as $0.05 \%(3 / 5935)$ ".

In the Discussion section, the last sentence of the first paragraph should read, "However, the incidence $(0.05 \%)$ of this condition had never been assessed before the current study".

The online version of the original article can be found under doi:10.1007/s00276-015-1455-2.

Dae Hee Han

lepolder@gmail.com

1 Department of Radiology, Seoul St. Mary's Hospital, College

of Medicine, The Catholic University of Korea,

505 Banpo-dong, Seocho-gu, Seoul 137-701, Korea

2 Department of Thoracic Surgery, College of Medicine,

The Catholic University of Korea, 505 Banpo-dong,

Seocho-gu, Seoul 137-701, Korea 